\title{
Fracionamento de carboidratos e proteínas de silagens de capim-elefante com casca de café, farelo de cacau ou farelo de mandioca ${ }^{1}$
}

\author{
${ }^{1}$ Projeto financiado pelo CNPq \\ 2 DTRA, UESB, Av. das Palmeiras, 491, Bairro Morumbi, CEP: 45.700-000, Itapetinga-BA. \\ 3 Programa de Pós-Graduação em Zootecnia, UFV, Viçosa, MG. Bolsista do CNPq. \\ ${ }^{4}$ Departamento de Zootecnia, UFV, Viçosa, MG. \\ 5 Programa de Pós-Graduação em Zootecnia, UESB, Itapetinga, BA. \\ ${ }^{6}$ Curso de Graduação em Zootecnia, UESB, Itapetinga, BA. Bolsista de Iniciação Científica do CNPq. \\ 7 Curso de Graduação em Zootecnia, UESB, Itapetinga, BA. Bolsista de Iniciação Científica da FAPESB. \\ 8 Pesquisador do CNPq.
}

Aureliano José Vieira Pires 2,8 , Gleidson Giordano Pinto de Carvalho ${ }^{3}$, Rasmo Garcia 4,8 , José Nobre de Carvalho Junior ${ }^{5}$, Leandro Sampaio Oliveira Ribeiro ${ }^{6}$, Daiane Maria Trindade Chagas ${ }^{7}$

RESUMO - Este experimento foi conduzido para avaliar as frações que compõem os carboidratos e as proteínas da silagem de capim-elefante com $15 \%$ casca de café, farelo de cacau ou farelo de mandioca. A adição dos co-produtos no momento da ensilagem foi realizada na base da matéria natural (peso/peso), com dez repetições por tipo de silagem. O maior teor de carboidratos totais foi observado na silagem com farelo de mandioca e o menor, na silagem com farelo de cacau, seguida das silagens controle e com casca de café. Maiores valores de carboidratos não-fibrosos $(\mathrm{A}+\mathrm{B} 1)$ também foram verificados para as silagens com farelo de mandioca. Os menores valores de fração indigestível $(\mathrm{C}, \% \mathrm{CT}$ ) foram observados para a silagem com farelo de mandioca, enquanto as silagens com casca de café e farelo de cacau apresentaram os maiores valores desta fração. A silagem com farelo de cacau apresentou os maiores valores de proteína bruta e foi seguida das silagens com casca de café, controle e com farelo de mandioca. A presença dos aditivos influenciou as frações protéicas da silagem de capim-elefante: os maiores valores de fração A $(\% \mathrm{~PB})$ foram determinados nas silagens controle e com farelo de mandioca. Apesar do maior valor protéico, as silagens com farelo de cacau e casca de café apresentaram os maiores valores de fração indigestível de proteína (C, \%PB). A adição de farelo de cacau e casca de café ao capim-elefante no momento da ensilagem aumenta as frações indigestíveis de carboidratos e de proteína da silagem. O farelo de mandioca ensilado com capim-elefante é um bom aditivo para a produção de silagem.

Palavras-chave: conservação de forragem, Pennisetum purpureum, resíduo, subproduto

\section{Fractioning of carbohydrates and protein of elephant grass silages with coffee hulls, cocoa meal and cassava meal}

\footnotetext{
ABSTRACT - This experiment was carried out to evaluate the fractions that compose carbohydrates and protein from elephant grass silage with $15 \%$ of coffee hulls, cocoa meal or cassava meal. The addition of residues at the ensilage moment was performed in natural matter basis (weight/weight), with ten replicates per treatment. The addition of residues at the ensilage moment was performed in natural matter basis (weight/weight), with ten repetitions per treatment. The total carbohydrates level of the silage with cassava meal was greater than that of other silages, with the lowest value observed to silage with cocoa meal, followed by control and silages with coffee hulls. Higher values of no-fiber carbohydrates (A + B1) were also verified for silages with cassava meal. Smaller values of the indigestible fraction $(\mathrm{C}, \% \mathrm{TC})$ were observed for silage with cassava meal, while silages with coffee hulls and cocoa meal showed higher values for this fraction. Higher CP values were verified in silage with cocoa meal, followed by the silages with coffee hulls, control and with cassava meal. The addition of by-products influenced the protein fractions, with higher values of fraction A (\%CP) in control silages and with cassava meal. Although with higher protein value, the higher protein indigestible fraction $(\mathrm{C}, \% \mathrm{CP})$ values were verified for silages with cocoa meal and coffee hulls. The addition of cocoa meal and coffee hulls to elephant grass at the ensilage moment produced silages with higher carbohydrate and protein indigestible fractions. The cassava meal ensiled with elephant grass showed to be a good addictive to silage production.
}

Key Words: by-product, forage conservation, Pennisetum purpureum, residue 


\section{Introdução}

O uso de forrageiras conservadas na forma de silagem é uma prática comum utilizada por produtores. $\mathrm{O}$ milho e o sorgo são ainda as forrageiras mais utilizadas para a produção de silagem, entretanto, o uso de gramíneas tropicais perenes para produção de silagens tem aumentado, tornando-se atualmente uma realidade em muitas propriedades rurais.

Segundo Evangelista \& Lima (2002), entre as gramíneas tropicais utilizadas na produção de silagem, o capimelefante se destaca por apresentar melhores características para ensilagem, com alto potencial produtivo, elevado número de variedades, grande adaptabilidade, facilidade de cultivo, boa aceitabilidade pelos animais e bom valor nutritivo quando em estádio jovem de maturidade. Apesar de todas estas vantagens, o capim-elefante apresenta baixo teor de carboidratos solúveis, o que pode comprometer a redução do $\mathrm{pH}$ após o fechamento do silo e, conseqüentemente, a produção de ácido lático para preservação da massa ensilada. Neste sentido, diversos trabalhos têm sido realizados em busca de alternativas para aumentar o aporte de carboidratos solúveis no momento da ensilagem do capim-elefante (Rodrigues et al., 2005; Carvalho et al., 2007a,b,c).

A casca de café, o farelo de cacau e o farelo de mandioca são alimentos encontrados em abundância em algumas regiões brasileiras, como a Região Nordeste, e apresentam potencial para utilização na ensilagem de capim-elefante. Informações sobre as frações de carboidratos e proteínas de silagens produzidas com co-produtos são importantes, pois, segundo Fox et al. (1992), além de possibilitar estimar com maior exatidão o desempenho dos animais, as estimativas das frações de carboidratos e proteínas permitem aumentar a eficiência de utilização dos nutrientes.

Realizou-se esta pesquisa para estimar as frações que compõem os carboidratos e as proteínas de silagens de capim-elefante contendo casca de café, farelo de cacau ou farelo de mandioca.

\section{Material e Métodos}

O capim-elefante (Pennisetum purpureum, Schum. cv. Napier) utilizado foi proveniente de uma capineira já estabelecida, pertencente à Universidade Estadual do Sudoeste da Bahia, UESB, em Itapetinga, Bahia. Aos 80 dias de rebrota, com altura média de $1,8 \mathrm{~m}$, o capim foi colhido, desintegrado em partículas de $2 \mathrm{~cm}$ e ensilado sem aditivo (silagem controle) ou com $15 \%$ de casca de café, farelo de cacau ou farelo de mandioca, em um delineamento inteiramente casualizado, com quatro tipos de silagem e dez repetições.

A adição dos co-produtos foi realizada com base na matéria natural (peso/peso), logo após o corte e a picagem do capim. A composição química do capim-elefante antes da ensilagem e dos co-produtos foi obtida segundo procedimentos descritos por Silva \& Queiroz (2002) (Tabela 1).

Em cada silo (tambores de metal com volume de $200 \mathrm{~L}$ ), foram colocados $90 \mathrm{~kg}$ da mistura fresca, em densidade de $450 \mathrm{~kg} / \mathrm{m}^{3}$. Após 60 dias de armazenamento, os silos foram abertos para coleta de amostras, as quais foram congeladas para posteriores análises. Parte das amostras foi descongelada à temperatura ambiente, acondicionada em sacos de papel e mantida em estufa de pré-secagem, por 72 horas a $65^{\circ} \mathrm{C}$. Em seguida, as amostras pré-secas foram processadas em moinho de facas com peneira com malha de $1 \mathrm{~mm}$.

As amostras foram encaminhadas para o Departamento de Zootecnia da Universidade Federal de Viçosa, onde foram analisadas nos Laboratórios de Forragicultura e Nutrição Animal.

A porcentagem de carboidratos totais (CT) foi obtida pela equação (Sniffen et al., 1992): CT $=100-(\% \mathrm{~PB}+\% \mathrm{EE}$ +\% cinzas); a de carboidratos fibrosos (CF), a partir da FDN corrigida para seu conteúdo de cinzas e proteínas $\left(\mathrm{FDN}_{\mathrm{CP}}\right)$; os carboidratos não-fibrosos (CNF), que correspondem às frações $\mathrm{A}+\mathrm{B} 1$, pela diferença entre os carboidratos totais $\mathrm{e}$ a $\mathrm{FDN}_{\mathrm{CP}}$ (Hall, 2003); e a fração C, pela FDN indigestível após 144 horas de incubação in situ (Cabral et al., 2004). A fração B2, que corresponde à fração disponível da fibra, foi obtida pela diferença entre a $\mathrm{FDN}_{\mathrm{CP}}$ e a fração $\mathrm{C}$.

Tabela 1 - Composição química dos alimentos antes da ensilagem, em porcentagem da matéria seca ${ }^{1}$

\begin{tabular}{lcccc}
\hline Item & $\begin{array}{c}\text { Capim- } \\
\text { elefante }\end{array}$ & $\begin{array}{c}\text { Casca de } \\
\text { café }\end{array}$ & $\begin{array}{c}\text { Farelo de } \\
\text { cacau }\end{array}$ & $\begin{array}{c}\text { Farelo de } \\
\text { mandioca }\end{array}$ \\
\hline Matéria seca & 28,3 & 89,8 & 86,0 & 88,8 \\
Matéria orgânica & 94,0 & 94,4 & 91,2 & 98,5 \\
Matéria mineral & 6,0 & 5,6 & 8,8 & 1,5 \\
Nitrógenio total & 0,9 & 1,2 & 2,4 & 0,4 \\
Extrato etéreo & 2,3 & 0,8 & 2,6 & 0,8 \\
FDNcp & 72,7 & 73,5 & 45,7 & 11,3 \\
Fibra em detergente & 43,0 & 57,7 & 33,8 & 6,6 \\
ácido & & & & \\
Hemicelulose & 29,8 & 15,8 & 11,9 & 4,7 \\
Celulose & 36,3 & 41,6 & 17,8 & 4,5 \\
Lignina & 5,4 & 16,1 & 15,6 & 1,0 \\
Carboidratos totais & 85,8 & 86,4 & 73,6 & 95,2 \\
Carboidratos & 17,1 & 18,3 & 39,6 & 92,4 \\
não-fibrosos & & & & \\
NIDN/NT & 22,2 & 52,3 & 44,2 & 12,5 \\
NIDA/NT & 6,0 & 38,6 & 39,7 & 10,2 \\
\hline
\end{tabular}

FDNcp: fibra em detergente neutro corrigida para cinzas e proteína; NIDN/NT: nitrogênio insolúvel em detergente neutro, em \% do nitrogênio total; NIDA/NT: nitrogênio insolúvel em detergente ácido, em \% do nitrogênio total. 
Os teores de proteína bruta e compostos nitrogenados insolúveis em detergente neutro (NIDN) e ácido (NIDA) foram determinados conforme descrito por Silva \& Queiroz (2002). A fração B3 da proteína foi obtida pela diferença entre NIDN e NIDA (fração C) e a proteína verdadeira solúvel em detergente neutro (frações B1+B2), pela diferença entre o nitrogênio insolúvel em ácido tricloracético (TCA), determinado conforme descrito por Pereira \& Rossi (1994), e o NIDN. O teor de nitrogênio não-protéico (fração A) foi calculado como a diferença entre o percentual do nitrogênio total na amostra e o valor de nitrogênio protéico contido no resíduo após o tratamento com o agente precipitante, TCA. Nesse procedimento de estimação do nitrogênio insolúvel em TCA e posterior obtenção da fração solúvel A, adicionou-se água destilada $(50 \mathrm{~mL})$ em aproximadamente $0,5 \mathrm{~g}$ de amostra, deixando-se o conteúdo em descanso por 30 minutos. Em seguida, adicionou-se solução de TCA $(10 \mathrm{~mL})$ a $10 \%$, deixou-se descansar por 20 a 30 minutos e filtrou-se o conteúdo em papel-filtro lavando-se o resíduo com $50 \mathrm{~mL}$ da solução de TCA diluída (aproximadamente $1 \%$ ). Procedeu-se então à estimação do teor de nitrogênio no resíduo + papel-filtro pelo método MacroKjedal. As frações protéicas foram estimadas como:

Fração A = Nt - Nr

Frações B1+B2 = NR - NIDN

Fração B3 = NIDN - NIDA

Fração $\mathrm{C}=\mathrm{NIDA}$

em que: $\mathrm{Nt}=$ teor de nitrogênio total da amostra; $\mathrm{Nr}=$ teor de nitrogênio insolúvel após o tratamento com solução de TCA; NIDN e NIDA = como definidos anteriormente.

Os dados foram submetidos à análise variância e à comparação de médias pelo teste Tukey a 5\% de probabilidade utilizando-se o programa Sistema de Análises Estatísticas e Genéticas - SAEG (Ribeiro Jr., 2001).

\section{Resultados e Discussão}

O maior teor de carboidratos totais $(\mathrm{P}<0,05)$ foi observado na silagem com farelo de mandioca (Figura 1) e o menor, na silagem com farelo de cacau, seguida das silagens com casca de café e controle, cujos valores foram intermediários. O menor teor de proteína bruta e extrato etéreo do farelo de mandioca contribuíram para os maiores valores de carboidratos totais observados na silagem produzida. $\mathrm{O}$ farelo de cacau, no entanto, por ter apresentado maior teor de proteína bruta e extrato etéreo, resultou em menor teor de carboidratos totais nas silagens. Carvalho et al. (2007a), ao estudarem a adição de farelo de cacau na ensilagem de capim-elefante, observaram redução dos teores de

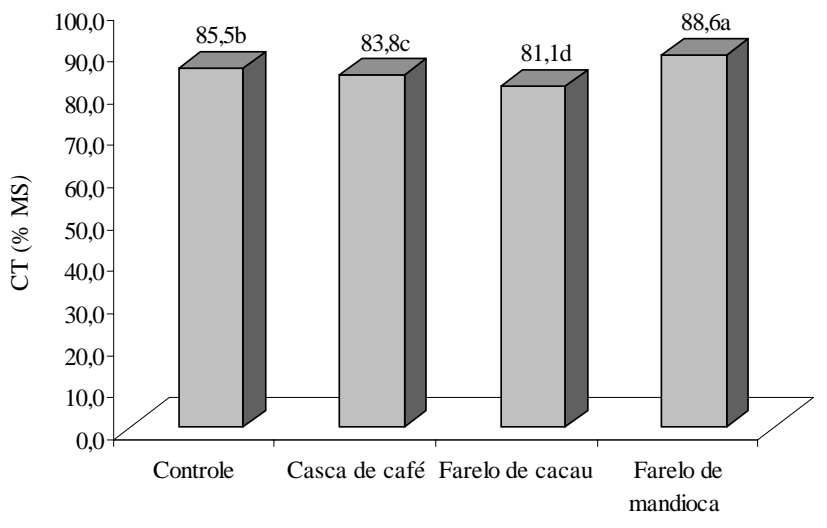

Figura 1 - Teores de carboidratos totais (CT) de silagens de capim-elefante contendo casca de café, farelo de cacau ou farelo de mandioca.Médias seguidas de mesma letra não diferem $(\mathrm{P}<0,0001)$ entre si pelo teste Tukey a $5 \%$

carboidratos totais, que foram de 81,$8 ; 79,6 ; 77,8 ; 76,9 \mathrm{e}$ $75,4 \%$, respectivamente, nas silagens com $0,7,14,21$ e $28 \%$ de farelo de cacau.

Seguindo a mesma tendência observada para os teores de carboidratos totais, as frações $\mathrm{A}+\mathrm{B} 1$ (\% CT) foram maiores $(\mathrm{P}<0,05)$ nas silagens com farelo de mandioca. De acordo com Carvalho et al. (2007a), alimentos com elevada fração $\mathrm{A}+\mathrm{B} 1$ são considerados boas fontes energéticas para aumento dos microrganismos ruminais que utilizam carboidratos não-fibrosos. Valadares Filho (2000), entretanto, destacou que, quando a fração $\mathrm{A}+\mathrm{B} 1$ compõe a principal fração dos carboidratos da dieta, é necessária a inclusão de fontes protéicas de rápida e média degradação no rúmen para a sincronização entre a liberação de energia e nitrogênio. $\mathrm{O}$ menor valor de fração $\mathrm{A}+\mathrm{B} 1$ foi verificado nas silagens com casca de café (Tabela 2).

A silagem controle destacou-se pelo maior valor da fração B2 $(68,9 \% \mathrm{CT})$, seguida das silagens com casca de café $(58,7 \%)$, farelo de mandioca $(54,4 \%)$ e com farelo de cacau $(50,9 \%)$. O maior valor de hemicelulose no capimelefante antes da ensilagem refletiu em maior fração B2 (\%CT) na silagem controle. Malafaia et al. (1998) concluíram que o valor de fração B2 nos alimentos está intimamente relacionado ao teor de FDN, o que explica os maiores valores desta fração na silagem controle. Apesar de a fração B2 ser potencialmente digestível, Russell et al. (1992) destacaram que volumosos ricos em fração B2 demandam nitrogênio não-protéico para atender às exigências de nitrogênio dos microrganismos fermentadores de carboidratos estruturais.

Os maiores valores da fração indigestível (C, \%CT) foram verificados nas silagens com casca de café e farelo 
Tabela 2 - Composição em carboidratos não-fibrosos (A+B1), componentes da parede celular disponíveis e fração indigestível da parede celular (C) de silagens de capim-elefante contendo casca de café, farelo de cacau ou farelo de mandioca

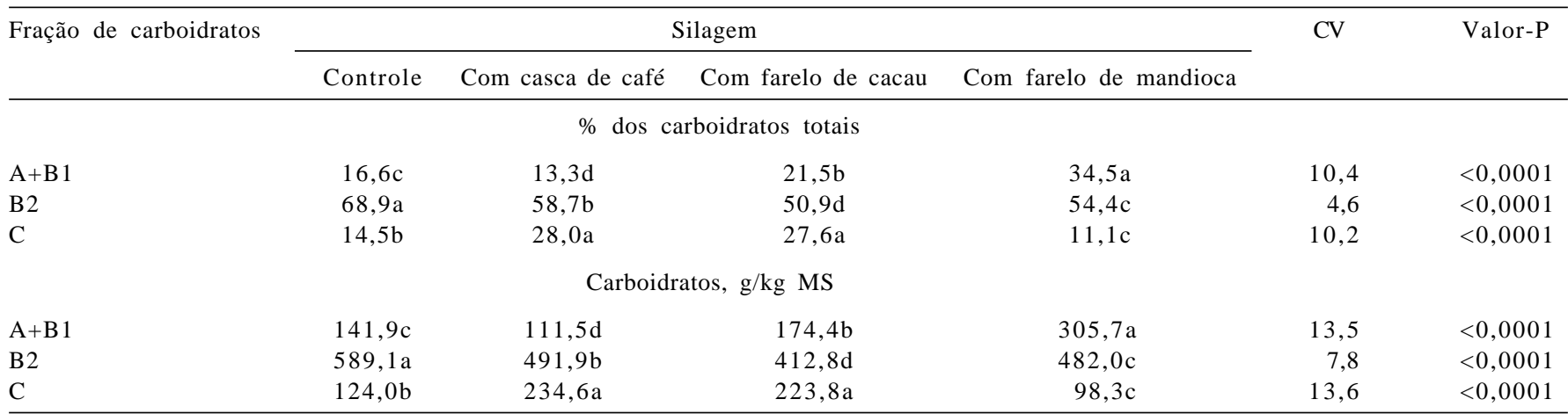

$\mathrm{CV}=$ coeficiente de variação $(\%)$.

Médias seguidas de mesma letra na linha não diferem estatisticamente a $5 \%$ pelo teste Tukey.

de cacau. É possível que os maiores valores de lignina nesses aditivos (Tabela 1) tenha acarretado maior fração C nestas silagens (Tabela 2). Diferentemente da fração B2, que está contida porção digestível da parede celular, a fração C (indigestível) afeta o consumo e pode prejudicar o desempenho animal. A silagem com farelo de mandioca foi a que apresentou menor valor desta fração e destacou-se entre as demais, com maior valor de carboidratos potencialmente digestíveis. Acréscimo linear na fração $\mathrm{C}$ (\% CT) foi observado por Carvalho et al. (2007a), que registraram aumento de 0,2 unidades percentuais para cada unidade de farelo de cacau adicionada ao capimelefante no momento da ensilagem.

A adição dos co-produtos na ensilagem teve efeitos sobre os teores de proteína bruta (Figura 2) das silagens. $\mathrm{O}$ maior valor foi observado na silagem com farelo de cacau $(7,4 \%)$, seguida das silagens com casca de café $(6,2 \%)$, controle $(4,7 \%)$ e com farelo de mandioca $(3,8 \%)$. A variação nos teores de proteína bruta das silagens pode ser atribuída aos valores desse nutriente no capim-elefante e nos aditivos antes da ensilagem (Tabela 1).

Alterações nos teores de proteína bruta em silagens de capim-elefante com aditivos também foram evidenciadas por Ferrari Jr. \& Lavezzo (2001), que, ao avaliarem doses crescentes de bagaço de mandioca na ensilagem de capimelefante, observaram redução linear nos teores de proteína bruta das silagens. $\mathrm{O}$ teor de PB do bagaço utilizado pelos autores foi de $2 \%$, o que ocasionou essa redução, uma vez que a inclusão do co-produto implica menores proporções de capim-elefante na silagem.

Houve efeito dos aditivos sobre o teor de nitrogênio não-protéico (fração A, \% PB) das silagens (Tabela 3), que foi maior nas silagens controle e com farelo de mandioca. Com a fermentação da massa ensilada, boa parte da

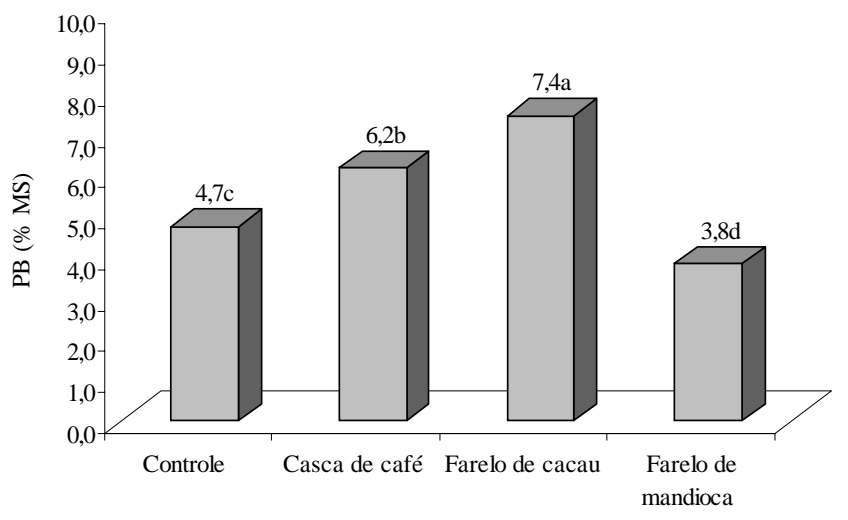

Figura 2 - Teores de proteína bruta (PB) de silagens de capimelefante contendo casca de café, farelo de cacau ou farelo de mandioca. Médias seguidas de mesma letra não diferem $(\mathrm{P}<0,0001)$ entre si pelo teste Tukey a $5 \%$.

proteína é convertida em nitrogênio não-protéico, em decorrência da proteólise. Contudo, os valores encontrados foram próximos das faixas normalmente registradas por outros autores em pesquisas com silagens de gramíneas (Carvalho et al., 2008).

As fraç̃oes B1 e B2 neste estudo foram consideradas fração única $(B 1+B 2)$ e se referem às proteínas solúveis e insolúveis verdadeiras. Os maiores valores foram observados nas silagens controle e com casca de café e os menores, na silagem com farelo de cacau. A constatação realizada por Carvalho et al. (2008) para a redução do valor de B1+B2 com a inclusão do farelo de cacau na ensilagem de capimelefante está de acordo com o resultado obtido neste estudo para a silagem com farelo de cacau, que apresentou menor valor.

Os valores de $\mathrm{B} 1+\mathrm{B} 2$ obtidos na silagem sem aditivo $(38,4 \%)$ foram superiores e os obtidos nas silagens com 
Tabela 3 - Frações protéicas de silagens de capim-elefante contendo casca de café, farelo de cacau ou farelo de mandioca

\begin{tabular}{|c|c|c|c|c|c|c|}
\hline \multirow[t]{2}{*}{ Fração protéica } & \multicolumn{4}{|c|}{ Silagem } & \multirow[t]{2}{*}{$\mathrm{CV}$} & \multirow[t]{2}{*}{ Valor-P } \\
\hline & Controle & Com casca de café & Com farelo de cacau & Com farelo de mandioca & & \\
\hline \multicolumn{7}{|c|}{$\%$ da proteína bruta } \\
\hline A & $42,9 a$ & $36,5 b$ & $35,6 b$ & $41,0 \mathrm{ab}$ & 8,0 & 0,0047 \\
\hline $\mathrm{B} 1+\mathrm{B} 2$ & $38,4 \mathrm{a}$ & $32,5 \mathrm{ab}$ & $22,2 \mathrm{c}$ & $29,4 \mathrm{bc}$ & 15,2 & 0,0005 \\
\hline B3 & $10,7 b$ & $11,6 \mathrm{~b}$ & $21,5 \mathrm{a}$ & $19,5 \mathrm{a}$ & 27,0 & 0,0017 \\
\hline $\mathrm{C}$ & $8,0 \mathrm{~b}$ & $19,4 \mathrm{a}$ & $20,7 \mathrm{a}$ & $10,1 \mathrm{~b}$ & 11,1 & $<0,0001$ \\
\hline \multicolumn{7}{|c|}{ g PB/kg MS } \\
\hline A & $20,29 \mathrm{a}$ & $22,6 \mathrm{a}$ & $26,3 \mathrm{a}$ & $15,6 \mathrm{~b}$ & 14,3 & $<0,0001$ \\
\hline $\mathrm{B} 1+\mathrm{B} 2$ & $18,0 \mathrm{a}$ & $20,2 \mathrm{a}$ & $16,4 \mathrm{~b}$ & $11,2 \mathrm{c}$ & 11,2 & $<0,0001$ \\
\hline B3 & $5,0 \mathrm{c}$ & $7,2 \mathrm{~b}$ & $15,9 \mathrm{a}$ & $7,4 \mathrm{~b}$ & 21,2 & $<0,0001$ \\
\hline $\mathrm{C}$ & $3,76 b$ & $12,0 \mathrm{a}$ & $15,3 \mathrm{a}$ & $3,8 \mathrm{~b}$ & 17,4 & $<0,0001$ \\
\hline
\end{tabular}

$\mathrm{CV}=$ coeficiente de variação $(\%)$.

adição de farelo de cacau e com farelo de mandioca foram próximos aos 22,4\% encontrados por Cabral et al. (2004) para a silagem de capim-elefante. Ribeiroetal.(2001) estimaram a fração B1+B2 para fenos de capim-tifton 85 ceifado aos $28,35,42$ e 56 dias de rebrota e relataram valores, respectivamente, de 33,$9 ; 35,03 ; 33,1$ e $31,5 \%$.

A fração B3 (\% PB) foi maior nas silagens com farelo de cacau e farelo de mandioca e menor nas silagens controle e com casca de café. Essa fração protéica (B3), apesar de digerível, possui taxa de degradação ruminal de 0,02 a 1,0\% $\mathrm{h}^{-1}$ (Sniffen et al., 2002). Já a fração considerada indigestível (C, \%CT), mensurada pela quantificação do teor de NIDA nas silagens, apresentou efeito significativo $(\mathrm{P}<0,05)$, com os maiores valores nas silagens com casca de café e com farelo de cacau. Esta fração protéica corresponde às proteínas associadas à lignina, complexos taninoproteína e produtos oriundos da reação de Maillard, altamente resistentes às enzimas microbianas e indigestíveis ao longo do trato gastrintestinal (Licitra et al., 1996). Os maiores teores de NIDA na casca de café e no farelo de cacau advêm, provavelmente, do processa-mento na obtenção destes co-produtos. Assim, embora apresentem bom teor protéico, a casca de café e o farelo de cacau possuem baixo aproveitamento da proteína, em decorrência dos elevados teores de NIDA, 38,6 e 39,7\%, respectivamente.

\section{Conclusões}

A adição de farelo de cacau ou casca de café ao capimelefante no momento da ensilagem aumenta as frações indigestíveis de carboidratos e proteína da silagem. $\mathrm{O}$ farelo de mandioca é um bom aditivo para a produção de silagem de capim-elefante.

\section{Literatura Citada}

CABRAL, L.S.; VALADARES FILHO, S.C.; DETMANN, E. et al. Taxas de digestão das frações protéicas e de carboidratos para as silagens de milho e de capim-elefante, o feno de capimTifiton-85 e o farelo de soja. Revista Brasileira de Zootecnia, v.33, n.6, p.1573-1580, 2004.

CARVALHO, G.G.P.; GARCIA, R.; PIRES, A.J.V. et al. Fracionamento de carboidratos de silagem de capim-elefante emurchecido ou com farelo de cacau. Revista Brasileira de Zootecnia, v.36, n.4, p.1000-1005, 2007a.

CARVAlHO, G.G.P.; GARCIA, R.; PIRES, A.J.V. et al. Valor nutritivo de silagens de capim-elefante emurchecido ou com adição de farelo de cacau. Revista Brasileira de Zootecnia, v.36, n.5, p.1495-1501, 2007b.

CARVAlHO, G.G.P.; GARCIA, R.; PIRES, A.J.V. et al. Valor nutritivo e características fermentativas de silagem de capimelefante com adição de casca de café. Revista Brasileira de Zootecnia, v.36, n.6, p.1875-1881, 2007c.

CARVALHO, G.G.P.; GARCIA, R.; PIRES, A.J.V. et al. Fracionamento de proteínas de silagem de capim-elefante emurchecido ou com farelo de cacau. Ciência Animal Brasileira, v.9, n.3, p.648-656, 2008.

EVANGELISTA, A.R.; LIMA, J.A. Silagens: do cultivo ao silo. 2.ed. Lavras: Universidade Federal de Lavras, 2002. 210p.

FERRARI JR., E.; LAVEZZO, W. Qualidade da silagem de capimelefante (Pennisetum purpurum Shum) emurchecimento ou acrescido de farelo de mandioca. Revista Brasileira de Zootecnia, v.30, n.5, p.1424-1431, 2001.

FOX, D.G.; SNIFFEN, C.J.; O`CONNOR, J.D. et al. A net carbohydrate and protein system for evaluating cattle diets: III. Cattle requeriments and diet adequacy. Journal of Animal Science, v.70, n.12, p.3578-3596, 1992.

HALL, M.B. Challenges with nonfiber carbohydrate methods. Journal of Animal Science, v.81, p.3226-3232, 2003.

LICITRA, G.; HERNANDEZ, T.M.; Van SOEST, P.J. Standardization of procedures for nitrogen fractionation of ruminant feeds. Animal Feed Science and Technology, v.57, n.4, p.347-358, 1996.

MALAFAIA, P.A.M.; VALADARES FILHO, S.C.; VIEIRA, R.A.M. et al. Determinação das frações que constituem os carboidratos totais e da cinética ruminal da fibra em detergente neutro de alguns alimentos para ruminantes. Revista Brasileira de Zootecnia, v.27, n.4, p.790-796, 1998.

PEREIRA, J.R.A.; ROSSI JR., P. Manual de avaliação nutricional de alimentos. Piracicaba: Fundação de Estudos Agrários Luiz de Queiroz, 1994. 34p. 
RIBEIRO JR., J.I. Análises estatísticas no SAEG (Sistema para análises estatísticas). Viçosa, MG: Universidade Federal de Viçosa, 2001. 301p.

RIBEIRO, K.G.; PEREIRA, O.G.; VALADARES FILHO, S.C. et al. Caracterização das frações que constituem as proteínas e os carboidratos e respectivas taxas de digestão, do feno de capimTifiton 85 de diferentes idades de rebrota. Revista Brasileira de Zootecnia, v.30, n.2, p.589-595, 2001.

RODRIGUES, P.H.M.; BORGATTI, L.M.O.; GOMES, R.W. et al. Efeito da adição de níveis crescentes de polpa cítrica sobre a qualidade fermentativa e o valor nutritivo da silagem de capim-elefante. Revista Brasileira de Zootecnia, v.34, n.4, p.1138-1145, 2005

RUSSELL, B.J.; O'CONNOR, J.D.; FOX, D.J. et al. A net carbohydrate and protein system for evaluation cattle diets: ruminal fermentation. Journal of Animal Science, n.12, v.70, p.3551-3581, 1992.

SILVA, D.J.; QUEIROZ, A.C. Análise de alimentos: métodos químicos e biológicos. Viçosa, MG: Imprensa Universitária, 2002. 235p.

SNIFFEN, C.J.; O'CONNOR, D.J.; Van SOEST, P.J. et al. A net carbohydrate and protein system for evaluating cattle diets: carbohydrate and protein availability. Journal of Animal Science, v.70, n.12, p.3562-3577, 1992.

VALADARES FILHO, S.C. Nutrição, avaliação de alimentos e tabelas de composição de alimentos para bovinos. In: REUNIÃO ANUAL DA SOCIEDADE BRASILEIRA DE ZOOTECNIA, 37. 2000, Viçosa, MG. Anais... Viçosa, MG: Sociedade Brasileira de Zootecnia, 2000. p.267-338. 